\title{
Prediction and optimizing residual stress profile induced by cold expansion in aluminum alloys using experimental design
}

\author{
M. Laredj, A. Miloudi \\ University of Djillali Liabes, SidiBel Abbès, Laboratory of LMSR Algeria \\ laredjmustapha@gmail.com,miloudidz@yahoo.fr
}

\section{A. Lousdad}

Laboratory of Mechanics of Structures and Solids (LMSS), Faculty of Technology-

Department of Mechanical Engineering University Djilali Liabes of Sidi Bel Abbes, B.P 89 Cité Ben M'Hidi - Sidi Bel-Abbes

22000 - Algeria

a_lousdad@yahoo.com

\section{Benguediab \\ University of Djillali Liabes, SidiBel Abbès, Laboratory of LMSR Algeria \\ benguediab_m@yahoo.fr}

\begin{abstract}
Cold expansion by hardening is a common process used in the aerospace industry to extend the fatigue lifetime of drilled assemblies due to the existence of a field of high compressive tangential residual stresses. The understanding and the control of the residual stresses are thus important, since it can be beneficial to improve the reliability and lifetime of the structures. The main objective of this work is to establish and validate a predictive model of residual stresses generated by cold hardening. This technique will be useful for industrial application since it allows the estimation of the fatigue lifetime of parts with respect to the process parameters. This tool can also be used to determine the optimal parameters in order to maximize the fatigue lifespan. An experimental setup was used to highlight the effect of the expansion degree, the thickness of the part and the yield strength on the residual stresse profiles. Moreover, the proposed mathematical models are used to determine the optimal values of the process parameters and predict the residual stress in order to achieve a maximum service life of cracked structure after repair. Also it aims to delay crack initiation and growth in riveted or bolted structures. Moreover, the modelling allows to highlighting the effect of these factors and their interactions on the residual stresses profiles.
\end{abstract}

KEYwORds. Cold expansion; Residual stress; Prediction; Experimental design; Interaction; Fatigue life.

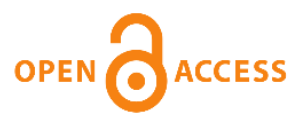

Citation: Laredj, M., Miloudi, A., Benguediab, B., Lousdad, A., Prediction and optimizing residual stress profile induced by cold expansion in aluminum alloys using experimental design, Frattura ed Integrità Strutturale, 48 (2019) 193-207.

Received: 31.10 .2018

Accepted: 18.02 .2019

Published: 01.04.2019

Copyright: (C) 2019 This is an open access article under the terms of the CC-BY 4.0, which permits unrestricted use, distribution, and reproduction in any medium, provided the original author and source are credited. 


\section{INTRODUCTION}

$\mathrm{F}$ atigue cracks in mechanical structures primarily begin at stress concentration tips such as rivet holes and / or geometric discontinuities. Hole cold expansion process is a very useful technique to extend fatigue life of structural assemblies. Hence, in the case of crack detection, a hole in the front of the crack will be created to reduce the concentration of local stresses leading to a delay of the propagation. This improvement is explained by lower notch sharpness and the presence of residual stresses introduced by the plastic deformation at the edge of the hole $[1,2]$. Hence, the role of compression residual stresses is to reduce the effective stress level.

Cold Expansion hardening (CEH) is a process used in the aerospace industry to extend the life of riveted and bolted structures by applying a high field of tangential compressive residual stresses. Consequently, residual stresses have a major role for determining the surface micro-cracks growth rate and thus on fatigue lifetime.

Therefore residual stress analysis is a mandatory step in the design and manufacture of components. Numerous studies based on experimental measurements $[3,4]$ or on numerical finite elements calculations $[5,6,7$, and 8$]$ studied separately the influence of several factors on the technique of cold expansion hardening.

J VOGVELL [2] simulated the expansion of a hole by a steel ball assumed undeformable on an aluminium 7075 T6 alloy plate. Numerical modelling is done using 3D finite elements. Three cases of plate thicknesses (2. 5and $10 \mathrm{~mm})$ and three degrees of expansion $(2,4$ and $6 \%$ ) were studied. The authors concluded that, increasing the degree of expansion does not have a significant influence on fatigue life.

Contrary, AMROUCHE and al [9] performed fatigue tests with the following degrees of expansion 1.7, 3.4 and $4.3 \%$ to study the influence of the number cycles leading to fatigue crack initiation for aluminium alloy $6082 \mathrm{~T} 6$ plate. The authors showed that the increase of the expansion degree leads to the retardation of crack initiation.

In AT ÖZDEMIR's work [10] fatigue tests were also carried out on aluminium alloy T651 8090 plates and aluminium alloy 7050 plate of thickness 1.6 and $5 \mathrm{~mm}$ respectively with 4\% expansion degree in addition to aluminium alloy 7010 of 19 $\mathrm{mm}$ thickness and 3\% of expansion degree to investigate the effect of the plate thickness. They showed that the 3\% expansion for the $19 \mathrm{~mm}$ thick plate gives a greater compression stress comparing to thinner plates of 1.6 and $5 \mathrm{~mm}$ with the expansion of $4 \%$.

Salvati and all [11] proposed eigenstrain field to the evaluation of residual strain within an additively anufactured nickel superalloy compressor blade that was subsequently subjected to shot peening treatment. Eigenstrain variation is described by a continuous function of the distance from the boundary of the bject in a twodimensional model of its cross-section. The authors showed that eigenstrain method for the in-plane strain reconstruction was successfully applied to a real case study of compressor blade section. The eigenstrain profile induced by shot peening was assessed, and the predicted residual elastic strain distribution compared to experimental measurements. Acceptable overall agreement was found.

DeWald and Hill [12] presents a methodology for predicting the residual stress within threedimensional parts caused by laser peening treatment. The eigenstrain is input into the finite element model in stated treatment areas where laser peening is applied. The authors concluded the model has a fair amount of agreement with the measurements over the range of geometry studied. But there is disagreement between the measurements and the predictions with respect to the relation between radius size and depth of compressive residual stress for the corner radius geometry. Renan and all [13] predict that the residual stresses arising from cold expansion by using two different finite element (FE) approaches and compare the obtained results to measurement data obtained by the contour method. The first FE approach considers process modeling, and includes elasticplastic behaviour. The second approach is based on the eigenstrain method and includes only elastic behavior. The results obtained from the FE models are in good agreement with one another as well as with the measurement data. The eigenstrain method was found to be very useful, providing generally predictions of residual stress. Both models were found to give reasonable residual stress estimates. Thus, the model results give confidence to estimate the residual stress.

The residual stresses produced by cold expansion hardening depend on several intrinsic or extrinsic factors of the material which complicate and make the modelling of the stresses difficult.

The present work deals with the influence of three factors that affect cold expansion hardening process and the distribution of stresses around a hole using 3D finite element model. The main parameters analyzed in this work are the thickness, the degree of expansion as well as the yield strength.

The experimental design methodology is used for modelling and predicting residual stresses in the input face. The approach allows the determination of the values of these factors which ensure the improvement of the service life. 


\section{PROCESS CHOICE}

$\mathrm{M}$ any cold expansion approaches have been developed and investigated according to the diverse expansion tools. The most widely used methods in practice are: ball expansion, direct mandrel expansion, hole edge expansion and split sleeve expansion processes $[14,15,05]$. In the present work the expansion by a mandrel with sleeve has been chosen in order to avoid direct contact between the workpiece and the mandrel to prevent both mandrel wear and the damage of hole surface.

The cold expansion hardening is carried out by inserting a mandrel with a sleeve through the hole of a tool (a conical mandrel with sleeve) of greater diameter " $D$ " than the initial diameter of the hole "d" as shown in figure (1). Split sleeve cold expansion is accomplished by pulling a tapered mandrel pre-fitted with a lubricated split sleeve through a hole. The function of the disposable split sleeve is to reduce mandrel pull force, ensure correct radial expansion of the hole, preclude damage to the hole and allow one-sided processing [16]. The expansion is obtained by interference of the initial hole diameter (d) and the maximum mandrel diameter (D) taking into account the sleeve thickness ( $t$ ). The degree of expansion is defined as a percentage by the following expression:

$$
D E \%=\frac{(D+2 T)-d}{d} \times 100
$$

$\mathrm{D}$ : Maximum mandrel diameter

$\mathrm{T}:$ Thickness of the sleeve

$\mathrm{d}:$ hole diameter before hardening

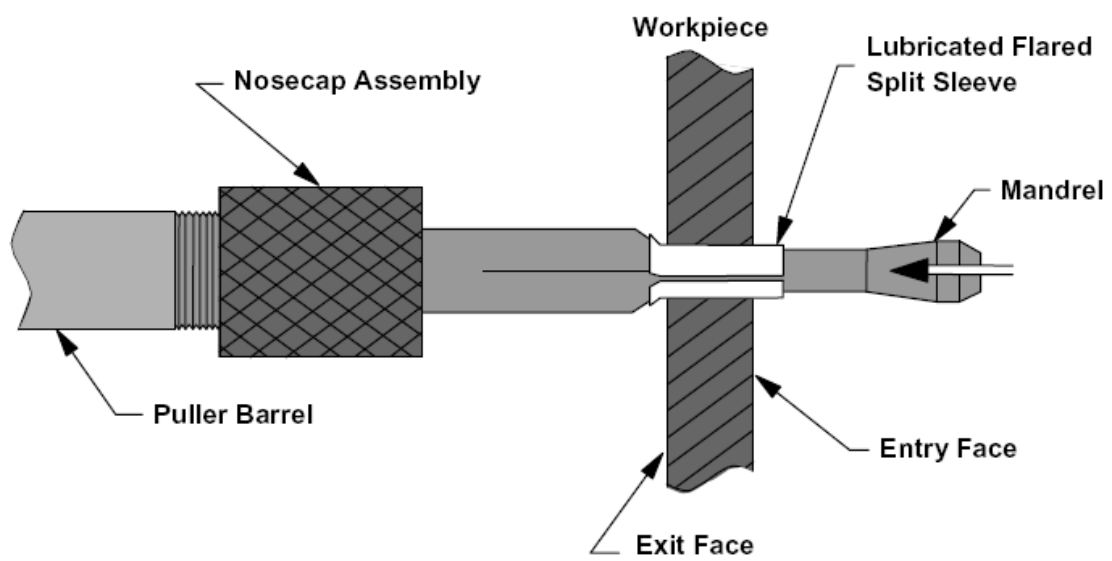

Figure 1: Drilling of cold expansion process overview [17].

\section{MODEL DESCRIPTION AND MECHANICAL PROPERTIES}

S

everal studies have been conducted to compare the results of $2 \mathrm{D}$ and $3 \mathrm{D}$ hole hardening finite element models [15, $05,18]$. All these previous studies consider the process as a generated axisymmetric stress state. A conclusion consensus of the different researchers' works that two-dimensional finite element models predict quietly different tangential residual stresses when compared to the surface results of 3D models. A 3-D model was preferred to the axisymetric 2-D one because of rectangular plate shape. This observation justifies the $3 \mathrm{D}$ models to simulate this phenomenon. The models consisted of square plates with $70 \mathrm{~mm}$ length, three thickness 3,5 and $7 \mathrm{~mm}$ with $6 \mathrm{~mm}$ diameter hole centrally located. Models had undergone a cold expansion hardening by mandrel with sleeve elastically deformable. The sleeve wall thickness is $0.25 \mathrm{~mm}$ and the mandrel diameter has a variable diameter depending on the degree of expansion $(2,4$ and $6 \%)$. The expansion was simulated using the commercial code ABAQUS 11 [19]. The materials used in our 3D simulation work are Aluminum alloys 6005-T6, 6082-T6 and AU 4G. The mandrel is supposed to be perfectly rigid. The sleeve has been modeled as an elastic body with the steel material properties (Young's modulus of $220 \mathrm{GPa}$ and a Poisson's ratio of 0.3 ). The friction coefficient between the contact surfaces is taken equal to 0.1 . The friction is generally present between the handle and the plate but often neglected between the mandrel and the handle since it is lubricated. 
A displacement in the $\mathrm{Z}$ direction is applied from the input face to the output face on the mandrel to simulate the expansion process. The Johnson-Cook is used for the numerical simulation in order to take into account the parameters of the dynamic hardening and the speed of plate deformation,

The Johnson-Cook parameters of the three aluminum alloys are shown in Table (1).

\begin{tabular}{lllllllll}
\hline & $\mathrm{A}(\mathrm{MPa})$ & $\mathrm{B}(\mathrm{MPa})$ & $\mathrm{n}$ & $\mathrm{c}$ & $\mathrm{m}$ & $\mathrm{T}_{\mathrm{f}}(\mathrm{K})$ & $\mathrm{Ta}(\mathrm{K})$ & $\varepsilon^{\cdot p}$ \\
AL AU 4G [20] & 350 & 440 & 0.41 & 0.0083 & 1 & 911 & 293 & 1 \\
AL 6005-T6 [21] & 270 & 134 & 0.52 & 0.015 & 0.859 & 893 & 293 & 1 \\
AL 6082-T6 [22] & 428 & 327 & 1.008 & 0.00747 & 1.31 & 855 & 293 & 1 \\
\hline
\end{tabular}

Table 1: Johnson-Cook parameters.

With:

$\mathrm{A}, \mathrm{B}$ and $\mathrm{n}$ : are constants that describe hardening $\mathrm{m}=$ hardening exponent

$\mathrm{T}_{\mathrm{f}}$ : Melting temperature

Ta: Ambient temperature

$\varepsilon^{p p}:$ is the reference strain rate
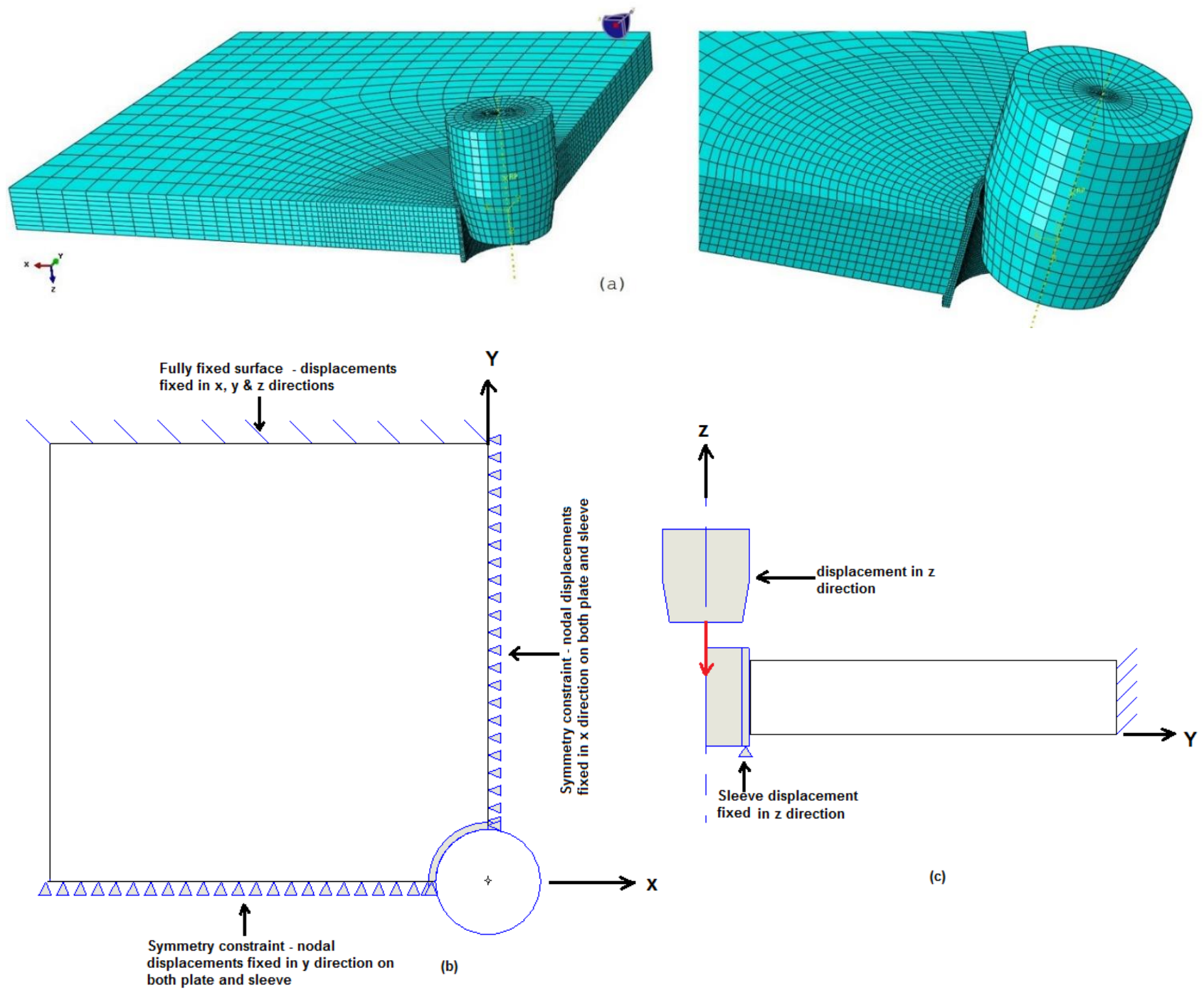

Figure 2: Finite element model boundary conditions: (b) plane xy; (c) plane yz. 
Due to the symmetry with respect to the X-Z, Y-Z planes, only a quarter of the specimen and sleeve are considered. This allows a much greater mesh refinement around the hole and reduces the required computational resources. A highly refined FE model is required to ensure convergence of the given solution at the area of high located deformation around the hole. For this reason, a non-uniform mesh distribution was used. Smaller elements were taken near the entrance and exit surfaces and longer elements away from the hole. The workpiece was discretized using linear brick elements (C3D8R) with reduced integration. This type of element is adapted in the case of elasto-plastic calculations and also is well conjugated with contact elements. In the case of a thickness equal to $3 \mathrm{~mm}$, this latter is divided into 10 elements. The model mesh is illustrated in figure (2-a) consisting of 17749 elements and 23043 nodes. Surface to surface contacts were used to represent the interaction between the different elements (hole surface - sleeve and sleeve - mandrel).

Figures (2-b-c) illustrate the geometry and the boundary conditions of the 3D FEA contact model of the mandrel and the handle.

Figure (3) shows the residual stress field with a 3.36\% cold expansion degree for the 6005T6 aluminum alloy with a $5 \mathrm{~mm}$ thickness. The deformed zone generates compressive residual stresses at the edge of the hole. We find that the residual circumferential stresses are not uniform through the thickness. Hence, Figures (4) shows that the level of compressive residual stresses on the entrance face is lower than that at mid-thickness. The stress varies between a maximum value of approximately $320 \mathrm{MPa}$ around the hole in the exit face and with minimum value of $140 \mathrm{MPa}$ at the entrance face. The difference in the residual stresses in the two specimen faces is explained by the level of retained expansion combined to the material volume carried by the mandrel movement during the cold expansion process. This result is in agreement with the works of Liu [23] and Elajrami [24]. These results lead to conclude that the entrance face is less resistant to fatigue than the exit face. Therefore, we chose the study of the residual stresses in the entrance face. Figure (5) illustrates an example of typical tangential residual stress distribution around an expanded hole. The important factors of the residual results profile (outputs simulations results) are summarized in Table (2).

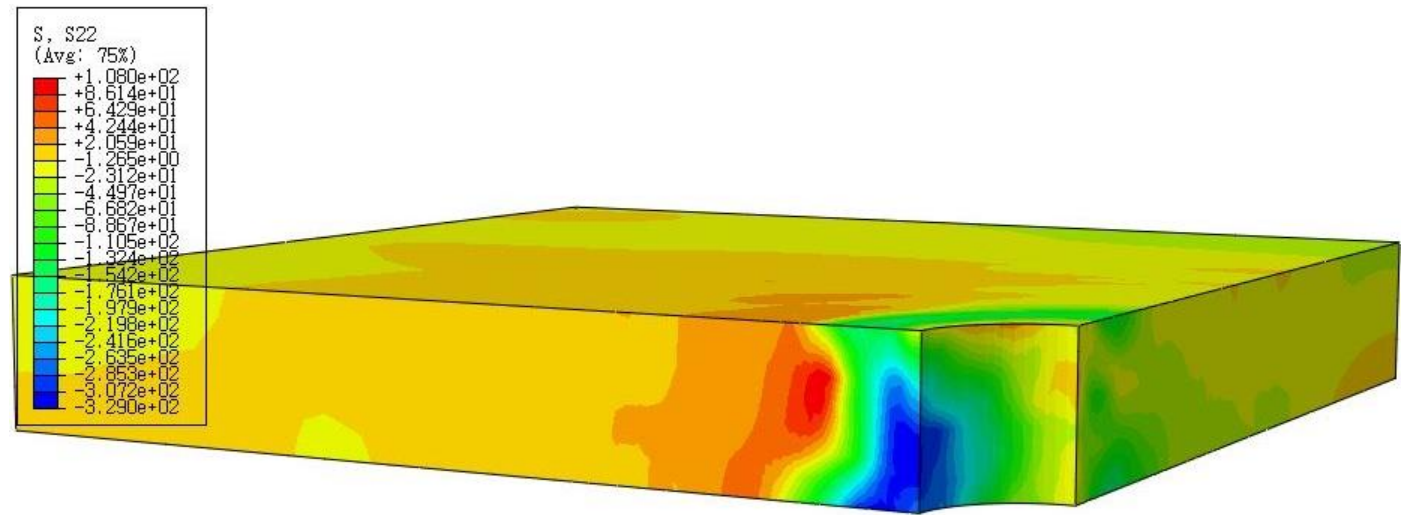

Figure 3: Distribution of circumferential residual stresses on the three faces

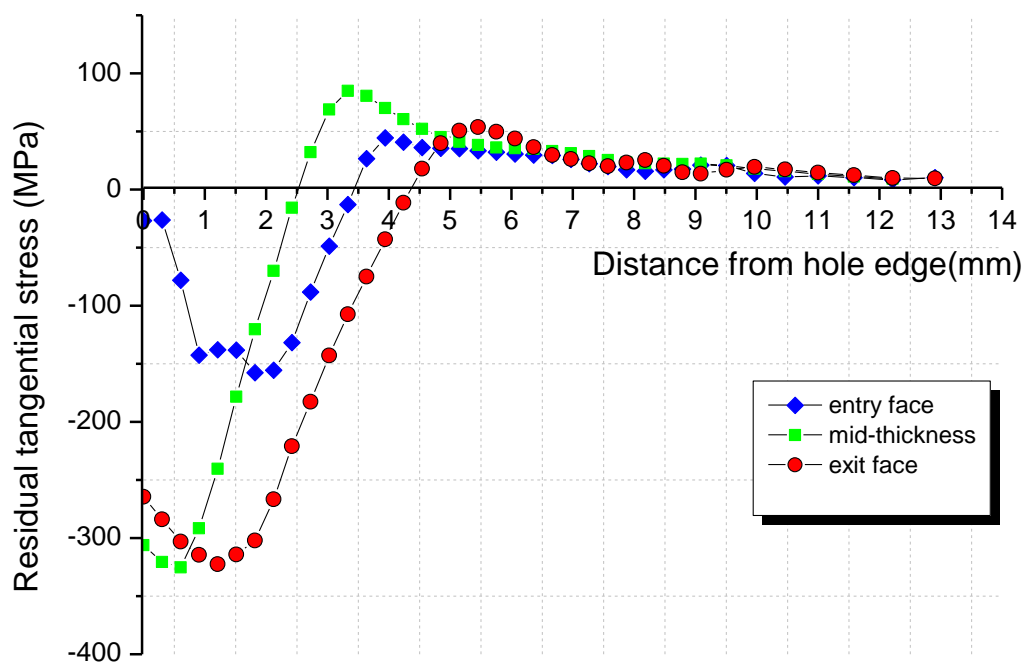

Figure 4: Tangential residual stress distribution at three different planes of the plate 


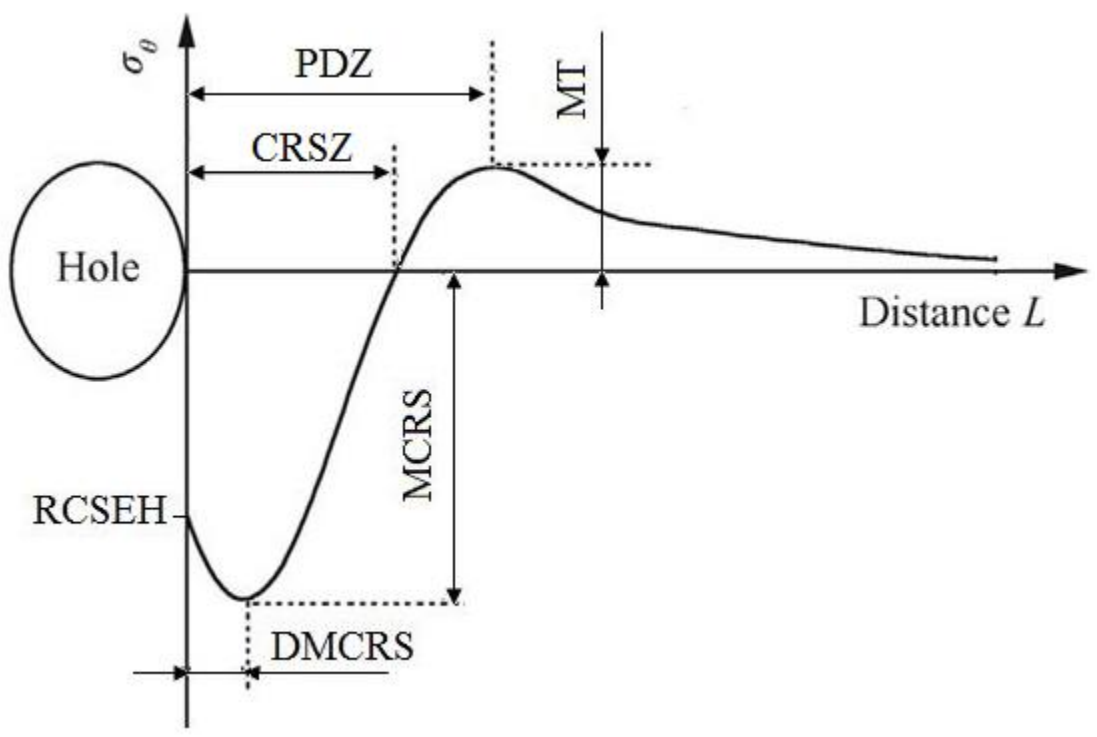

Figure 5: Typical distribution of tangential residual stress around an-expanded hole

\begin{tabular}{lll}
\hline & Factors & Outputs results \\
1 & CRSEH & CompressiveResidual Stress at the Edge of the Hole \\
2 & MCRS & Maximum Compressive Residual Stresses \\
3 & DMCRS & The Depth of the Maximum Compressive Residual Stress \\
4 & CRSZ & The Compressive Residual Stress Zone \\
5 & MT & The Maximum Tension \\
6 & PDZ & The Plastic Deformation Zone \\
\hline
\end{tabular}

Table 2: Output simulations results

\section{EXPERIMENTAL DESIGN APPROACH}

7 he experimental design is necessary to identify relevant information to establish a relationship between the input variables thickness $(\mathrm{t})$, cold expansion (Ce) and yield strength $(\mathrm{Ys})$ ) and the output variables (CRSEH, MCRS, DMCRS, CRSZ, MT and PDZ). In order to predict the amount of residual stresses each parameter was tested at three different levels: the thickness $(3,5,7 \mathrm{~mm})$, cold expansion $(2,4,6 \%)$ and yield strength $(270,349.25,428.5 \mathrm{MPa})$.

The responses were calculated using the finite element method. The experimental design matrix of the experiments is given by MODDE 5.0 (Modeling and Design) software [25-26].

We have adopted a complete experimental design [27] of three factors at two levels. The mode of the experimenter is quadratic and has the following form:

$$
y=a_{0}+\sum_{i=1}^{3} a_{i} x_{i}+\sum_{1 \leq i<j \leq 3} a_{i j} x_{i} x_{j}+\sum_{i=1}^{3} a_{i i} x_{i}^{2}+e
$$

Where $i, j$ vary from 1 to the number of process variables (3), y is the response of the process. The coefficient is the average of all the responses for the whole experiment; The coefficients represent the effect of the variable and are the regression coefficients that represent the effects of the interactions of the variables and $\mathrm{e}$ is the experimental error. The polynomial model proposed by MODDE 5.0 describes the variations of the response function to the factors $(\mathrm{Ys}),(\mathrm{Ce})$ and $(\mathrm{t})$ is of the following form:

$$
\text { response }=a_{0}+a_{1} t+a_{2} Y s+a_{3} C e+a_{12} t . Y s+a_{13} t \cdot C e+a_{23} Y s \cdot C e+a_{11} t^{2}+a_{22} Y s^{2}+a_{33} C e^{2}
$$


The experimental plans used in this study are a complete quadratic plan which a mathematical model of the second degree. By removing the non-significant effects we obtain the following mathematical models:

$$
\begin{aligned}
& \begin{aligned}
\text { CRSEH } & =-114.75-5.56(t)+38.64(C e)-15.46(Y s)+9.86(t) \cdot(Y s)+ \\
& +13.59(C e) \cdot(Y s)+7.7(t)^{2}+9.08(C e)^{2}+20.38(Y s)^{2}
\end{aligned} \\
& \begin{aligned}
& M C R S=-238.07+21.49(t)+8.11(C e)-26.34(Y s)+7.43(t) \cdot(C e)++12.82(t)^{2}+5.9+16.15(Y s)^{2} \\
& \text { DMCRS }=1.44+0.08(t)+0.49(C e)-0.2(Y s)+0.08(t) \cdot(C e)-0.03(C e) \cdot(Y s)+0.02(t)^{2}-4(C e)^{2}+0.04(Y s)^{2}
\end{aligned} \\
& \text { CRSZ }=3.38+0.16(t)+0.43(C e)-0.29(Y s)+0.14(t) \cdot(C e)-0.11(t)^{2}-0.17(C e)^{2}-0.1(Y s)^{2} \\
& M T=47-7.5(t)+14.23(C e)+8.05(Y s)-2.15(t) \cdot(C e)+4.17(t) \cdot(Y s)+2.13(t)^{2}+0.32(C e)^{2}-0.3(Y s)^{2} \\
& P D Z=3.88+0.09(t)+0.5(C e)-0.21(Y s)+0.13(t) \cdot(C e)-0.08(t) \cdot(Y s)+ \\
& \quad+0.03(C e) \cdot(Y s)-0.019648(t)^{2}-0.13(C e)^{2}-0.05(Y s)^{2}
\end{aligned}
$$

\section{ANALYSIS OF THE RESULTS}

$\mathrm{F}$ rom the graphical analysis we can determine the influence of each factor on the response by plotting the response variation according to these factors.

The evolution of surface residual stresses at the edge of the hole after expansion as a function of the thickness $(t)$, the degree of expansion and the yield strength are presented respectively in the figures (6-a), (6-b) and (6-c). The analysis of Figure (6-a) shows that an increase in the thickness causes an increase of the residual stresses (absolute value) at the edge of the hole after expansion CRSEH.
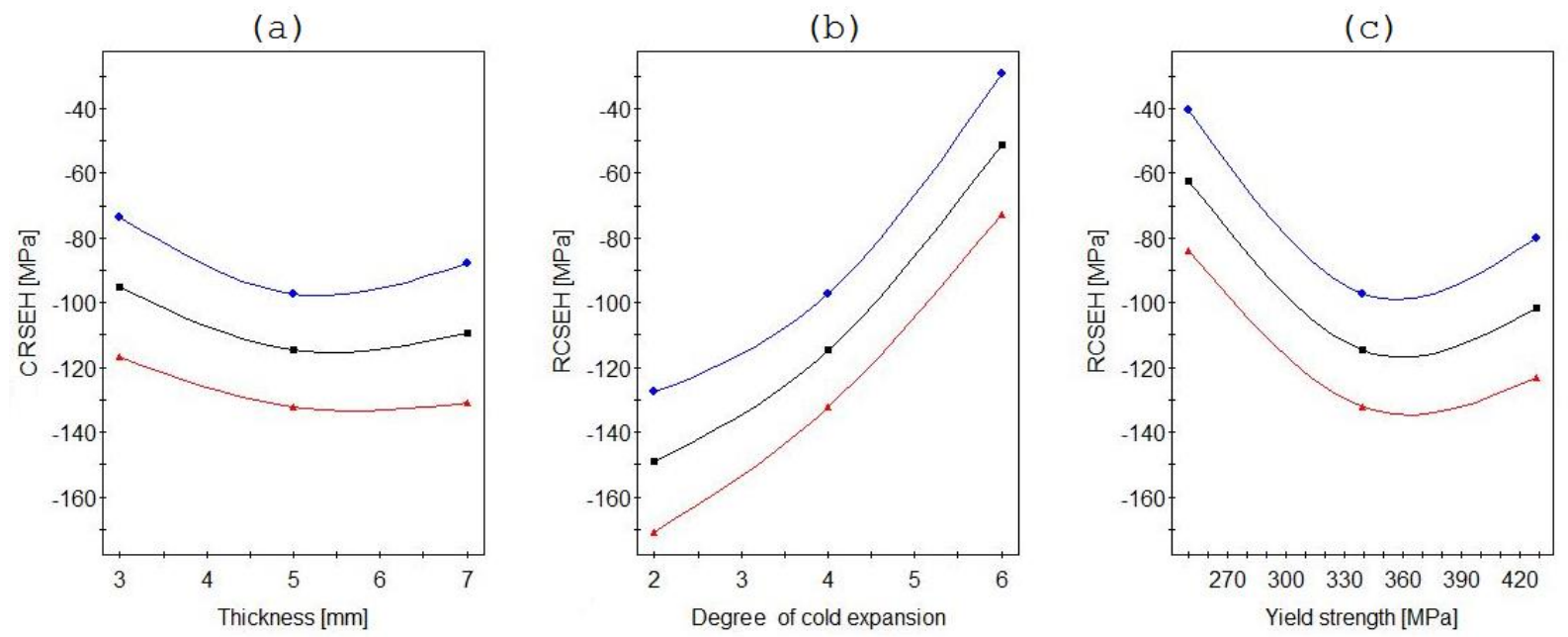

Figure 6: The compressive residual stress at the edge of the hole after expansion

From the results one can deduct the existence of the critical thickness $(t=4.92 \mathrm{~mm})$ of the material and beyond this value the CRSEH is almost independent of this geometrical parameter. The result show a good agreement with V. NIGRELLI et al work [28] which illustrated through FE analysis carried out on plate thicknesses of 3, 5 and $10 \mathrm{~mm}$ considering a 
constant hole diameter $\mathrm{d}=5.8 \mathrm{~mm}$. The authors concluded that the increase of thickness leads to an increase of residual compression stresses at the edge of the hole.

In the following the influence of the (Ce) on the CRSEH is investigated. This study was carried out for an expansion degree ranging from 2 to $6 \%$.

Figure (6-b) illustrates the variation of the CRSEH as function of the (Ce). We found that, the stresses decrease with the increase of the expansion degree (absolute value).

Moreover, the effect of yield strength according to the variation (CRSEH) is analysed and illustrated in figure (6-c). This figure shows that an increase in the yield strength reduces the CRSEH after expansion. The process is valid between [240$340 \mathrm{MPa}$. However, in the range [340-430 MPa] the (CRSEH after the expansion increases slightly depending on the value of yield strength. It should be noted that no experimental or numerical study had examined the effect of the degree of expansion and the yield strength on CRSEH.

Regarding the second factor (MCRS), which represents an important parameter for the residual stress profiles, we studied the variation this factor with respect to the $(\mathrm{t}),(\mathrm{Ce})$ and $(\mathrm{Ys})$. The analysis results are illustrated respectively in figures (7-a), (7-b) and (7-c). We find that an increase of the thickness and the degree of expansion lead to reducing the maximum compressive residual stresses (in absolute value) which is less marked in the case of the degree of expansion. Hence, the increase of these parameters leads to the increase of the lifetime of the structure. These results are in agreement with the findings research of Z. SEMARI and J. VOGWELL [29-2] concluding that the compression stresses are inversely proportional to the degree of expansion. Unlike the other effects, we found that the increase of the yield strength causes an increase of the MCRS (in absolute value) which confirms the conclusions of others authors [30 .1], performing several tests and simulations on Aluminium alloys and some steels.

(a)

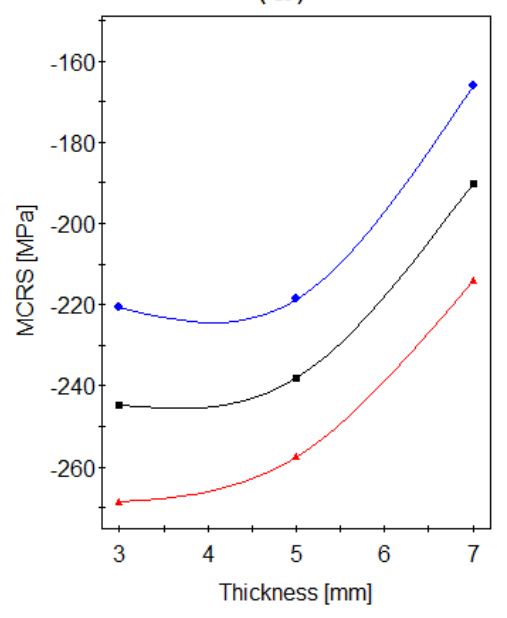

(b)

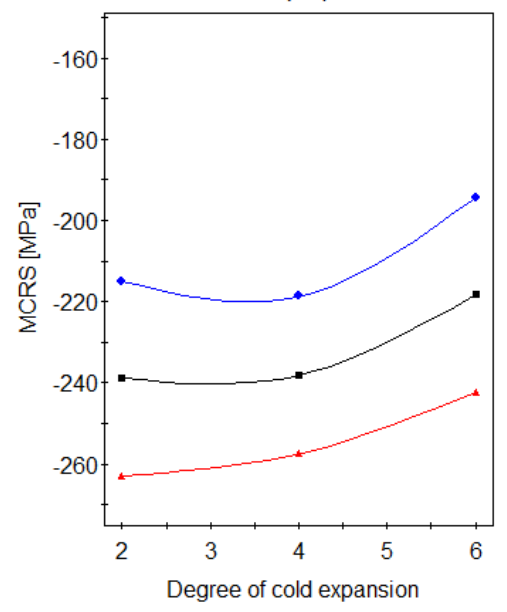

(c)

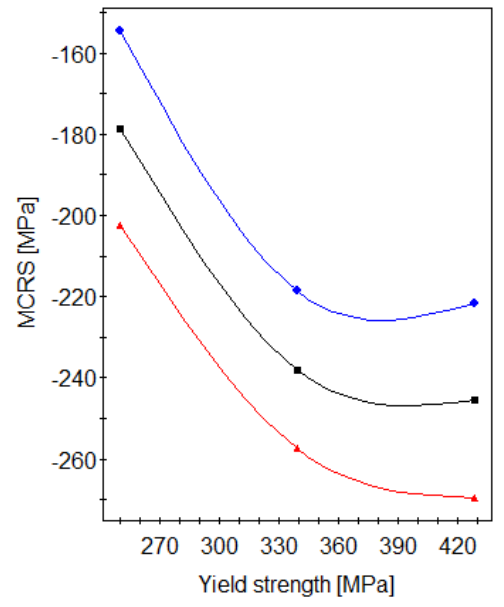

Figure 7: The variation of the maximum compressive residual stress after expansion

In the following section, we have studied the effects of the ( $t)$, (Ce) and (Ys) on the depth variation of the maximum compressive residual stress. The examination of the figure (8-a), permit us to notice that the thickness has a minor influence on the compressive residual stress. In fact the increase of thickness by $133 \%$ leads to an increase of 7.05\% in the (DMCRS). The Figure (8-b) shows clearly that the degree of expansion has a higher influence on DMCRS. According to the figure (8c), we notice that the increase of the yield strength leads to a decrease of DMCRS.

In this part, we are interested in studying the evolution of other important parameter on residual stress profiles which is the compressive residual stresses zone.

The results in the Figure (9-a) indicate that an increase of the thickness leads to an increase of CRSZ. Consequently, the use of thicker structure conducts to an important improvement of lifetime. Therefore we can also indicates that there exist a critical thickness $(t=4.93 \mathrm{~mm})$ beyond which the CRSZ is almost independent of this geometrical parameter. The results obtained are consistent with the work of V. NIGRELLI, A.T. ÖZDEMIR and [28-10].

Regarding the degree of expansion, we notice that it had an important effect on the compressive residual stresses zone. These results are in agreement with the results of A.AMROUCHE and M. SU $[32,31]$ who found that the degree of expansion has a significant influence on CRSZ. Also, the authors had shown, based on experimental measurements and finite element numerical calculations study that the growth of CRSZ stops at Ce $=5 \%$. It can be interpreted as the convergence difficulty of 3D calculation. On the other hand, beyond the degree of expansion value 4 the influence of the 
latter on CRSZ is insignificant. Consequently, an increase in the degree of expansion by $50 \%$ leads only to an increase of $7.46 \%$ of the compressive residual stresses zone.

(a)

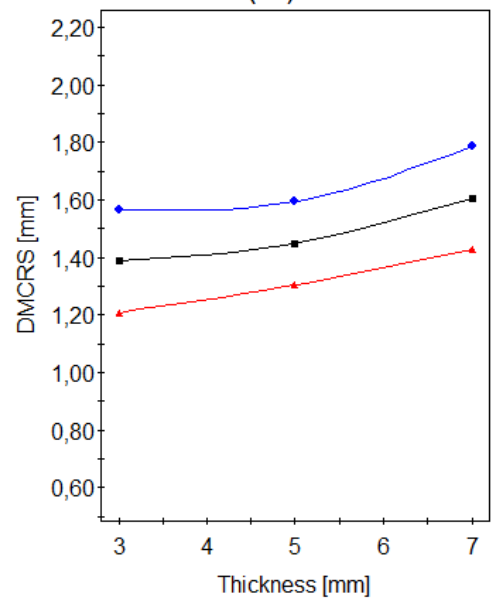

(b)

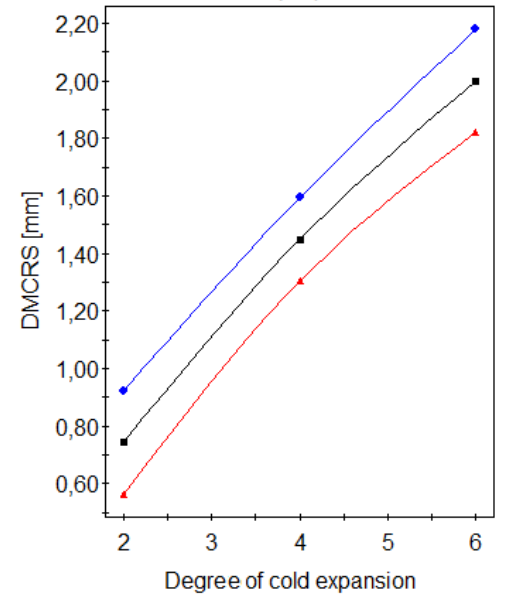

(c)

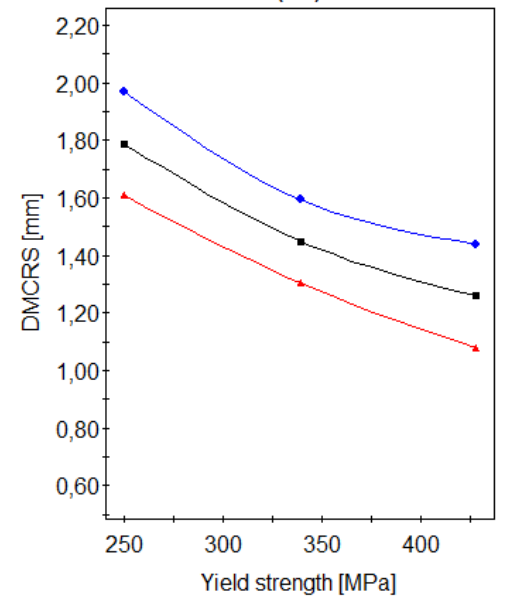

Figure 8: The depth variation of the maximum compressive residual stress in

Figure (9-c) illustrates the effect of the yield strength on CRSZ. Contrary to the other parameters, an increase in the yield strength leads to a decrease of the compressive residual stresses zone. In fact, a $72 \%$ increase in the yield point leads to a $20 \%$ decrease in the CRSZ. It had been demonstrated that the mechanical characteristics have an influence on the distribution of the circumferential residual stresses.

Several investigations carried by Z. SEMARI and M. SU [29-31] have focused on the study of the effect of the mechanical characteristics on residual stress profiles. Therefore all studies agree that the increasing of the yield strength causes a decrease in CRSZ.

(a)

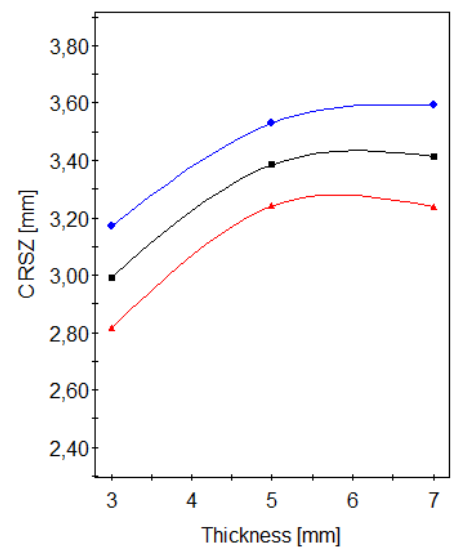

(b)

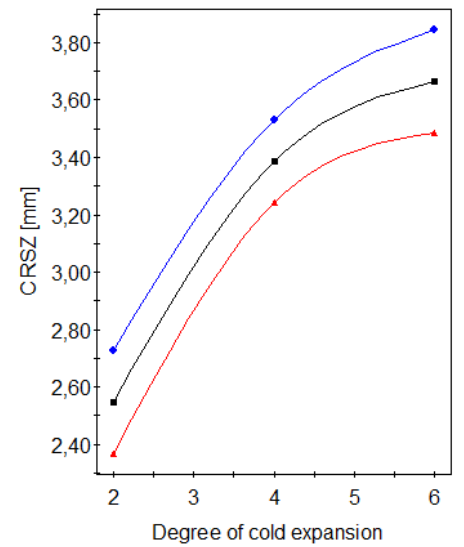

(c)

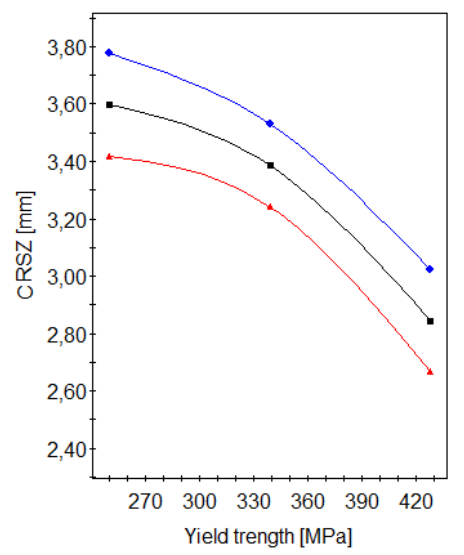

Figure 9: The variation of the compressive residual stresses zone

The evolution of the plastic deformations zone as a function of the (t), (Ce) and (Ys) are presented respectively in the figures $(10-\mathrm{a}),(10-\mathrm{b})$ and $(10-\mathrm{c})$.

Figure (10-a) illustrates the evolution of the plastic deformations zone with respect to the thickness. We note that the increase of the thickness causes a small increase of PDZ. These results are in agreement with the work of V. NIGRELLI [28].

Figure (10-b) illustrates the effect of the degree of expansion on the PDZ. We see that an increase of the expansion degree leads to an increase of the plastic deformations zone which provokes the deceleration of the propagation kinetics of the defects and thus the increase of the lifetime of the structures. These results are in accordance with the work results of $\mathrm{Z}$. SEMARI [29]. 
Figure (10-c) shows the variation of the plastic deformations zone as function of the yield strength. According to this figure we note that the yield strength increase results a small decrease of PDZ which is verified by the results of M. Su and al [31] by performing expansion by a numerical simulation for different degrees of expansion: $1.7,3.4,4.3,5$, and $6 \%$ on aluminium alloys 6082, 6005 and steel A42. They have demonstrate that crack initiation can be obtained by a lower number of cycles in the case of the yield strength increasing than by the increase of the degree expansion.

(a)

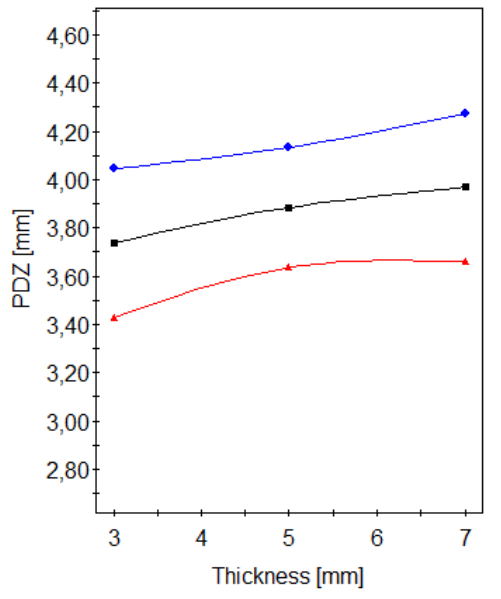

(b)

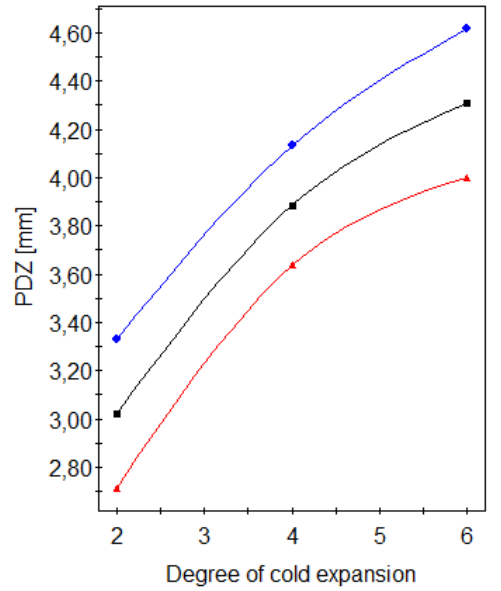

(c)

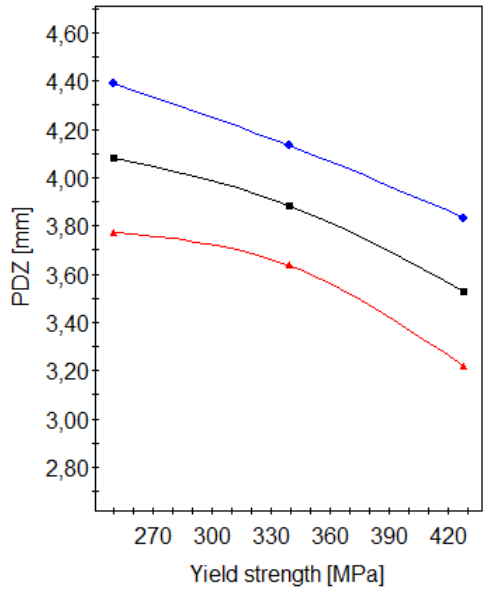

Figure 10: The plastic deformations zone

In the last analysis we study the evolution of the maximum tension according to the three previous parameters. In figure (11-a) we observe that the decrease in the MT caused by increasing of thickness. Thus, the thicker structure presents the lower MT. On the other hand, in Figures (11-b) and (11-c) we observe that, an increase of the degree expansion and the yield strength leads to an increase of the maximum tension. This effect is more marked in the case of the expansion degree.

(a)

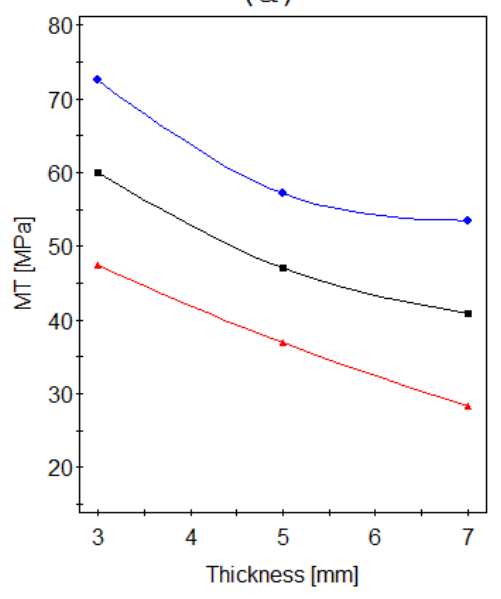

(b)

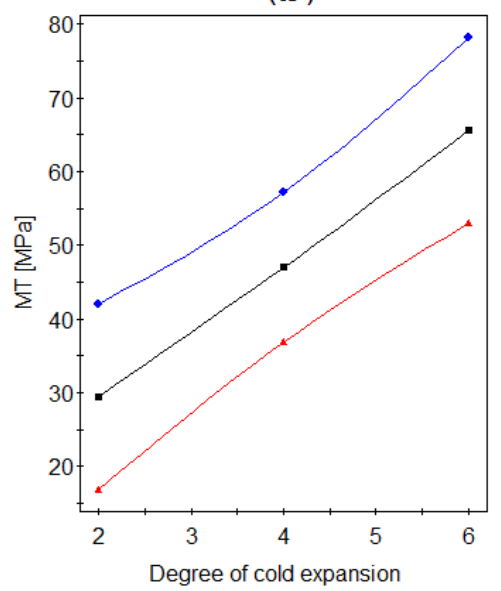

(c)

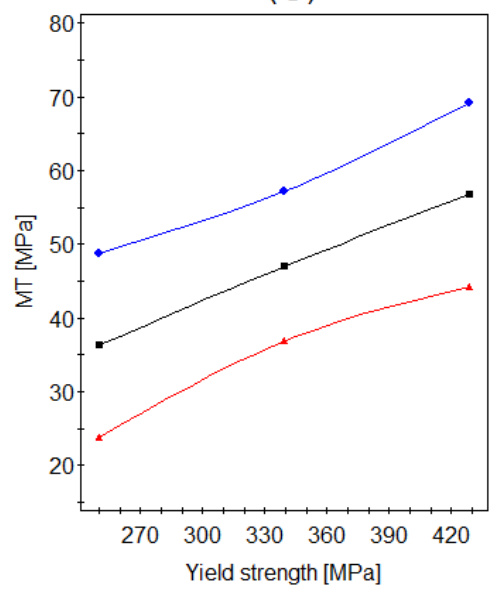

Figure 11: The variation of the maximum tension after the expansion

In the first case of interactions, the parameters variation of residual stress profiles according to the three factors: (Ce), (Ys) and $(t)$ is investigated. Therefore, the plan calculates the effects of both factors and their interaction using a regression model. In this study, we only present the prediction curves shown in the figures $(12,13)$ which show the influence of the most important points in the residual stress profile enumerated as following:

- The maximum compressive residual stresses

- The compressive residual stresses zone.

Figure (12) shows the predicted response of the MCRS according to the variation of the three factors. The investigation of this curve shows that, to produce a maximum value of compressive residual stress (in absolute value) it is necessary to 
maintain value of the degree of expansion between 3 and $4 \%$, the thickness between 3 and $6 \mathrm{~mm}$ and to keep the yield strength between 345 and $430 \mathrm{MPa}$.
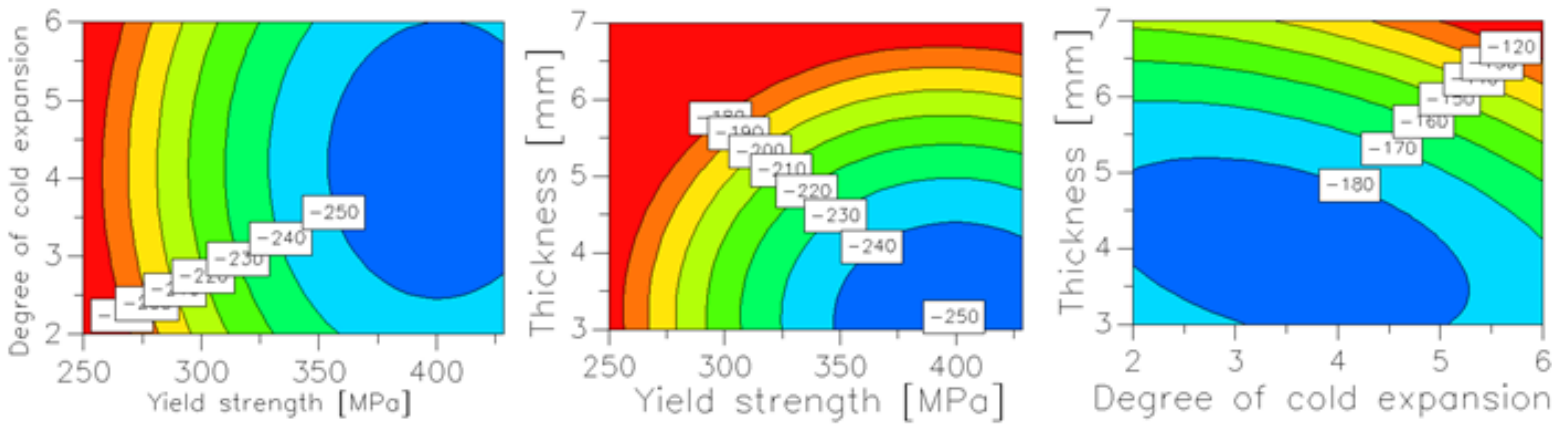

Figure 12: prediction of maximum compressive residual stress as a function of the three factors

In the last of interaction analysis, we focus on the compressive residual stress zone variation according to the three factors as shown in figure (13). The results clearly show that the increase of the degree of expansion and the thickness cause to a larger area of the CRSZ. However the reduction of the yield strength leads to an increase of this zone.
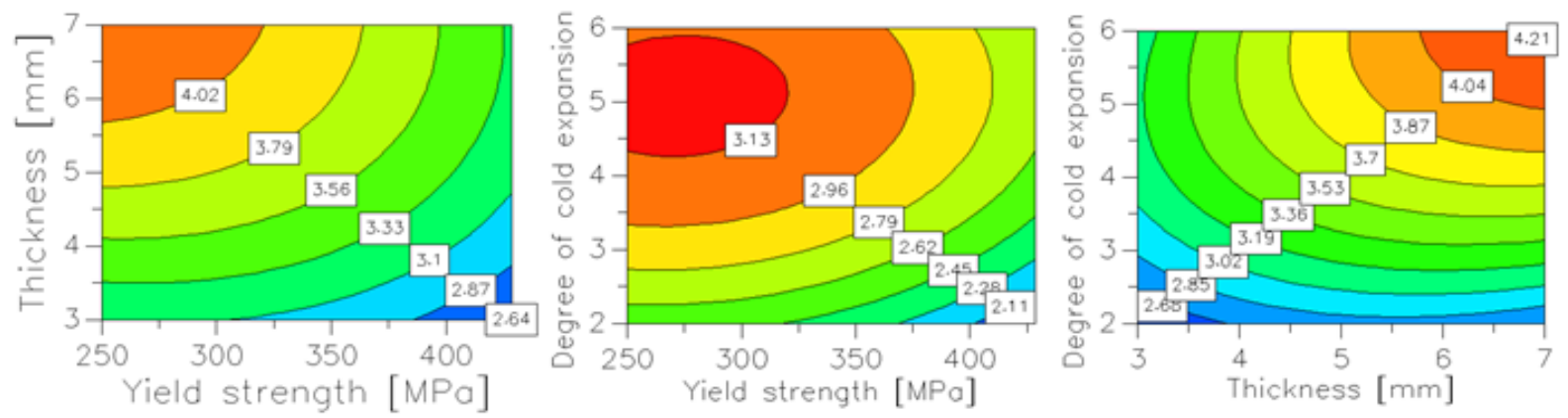

Figure 13: prediction of the compressive residual stresses zone.

By introducing the results in the MODDE 5.0 software to examine the different effects, the results given in FIGS. 14 and 15 corresponding respectively to the maximum compressive residual stress and the compressive residual stress zone were obtained. The effects of factors are presented using a bar graph. This diagram gives the effects in descending order of their importance in absolute value.

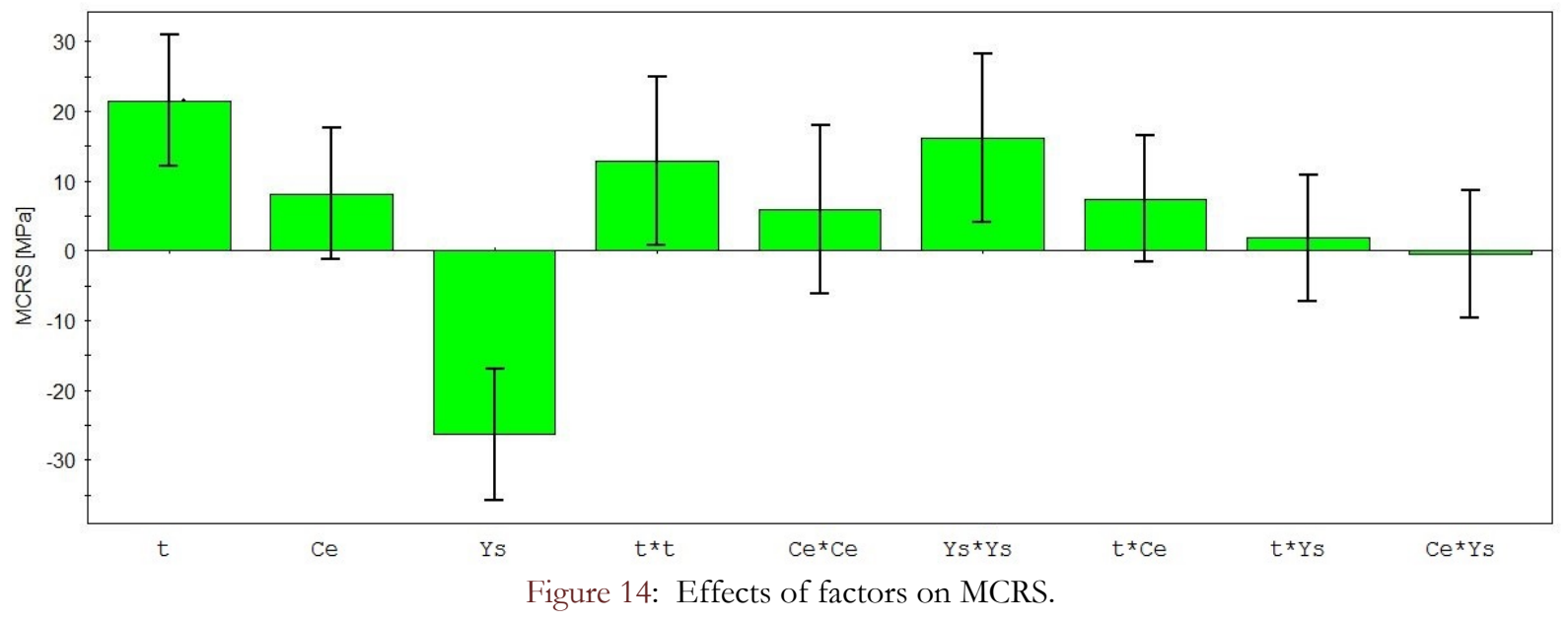

The analysis of these figures shows that the classification of dominant factors on the maximum compressive residual stresses is as the following: (Ys), (t) and (Ce).

On the other hand, for the case of the compressive residual stresses zone and the other points of the residual stress profile, the order of dominant factors are as following: (Ce), (Ys) and (t). 
Hence, we note that the effect of the degree of expansion on the improvement of the service life is more significant than the yield strength and the thickness.

From the obtained models we can determine the optimal values of the various factors $(\mathrm{t}),(\mathrm{Ce})$ and $(\mathrm{Ys})$ to predict the residual stresses obtained from factor values.

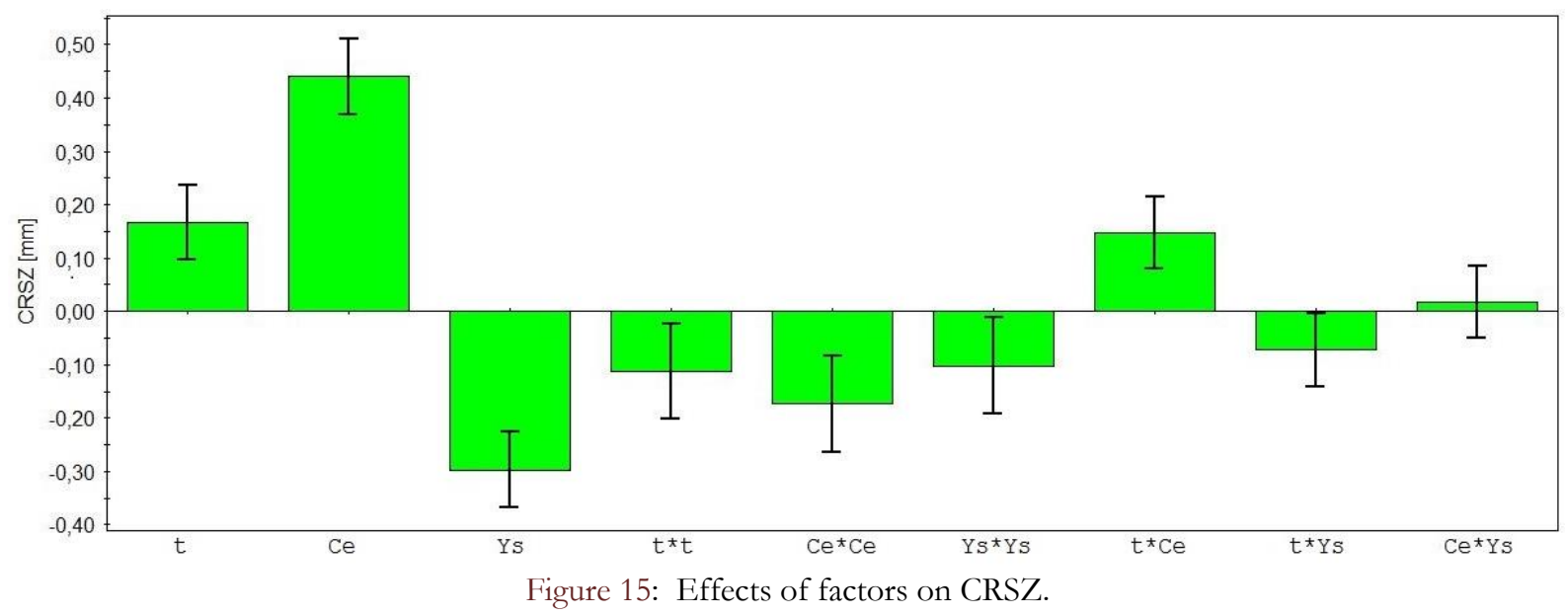

According to the analysis performed by the "modde5.0" software we can verify easily the optimal points of the responses. Consequently, according to the table (3) these values are obtained by maximizing the residual stress profile. The process can be carried out by the experiment which comprises the values of the thickness equal to $4.93 \mathrm{~mm}$, the degree of expansion which is equal to $4.04 \%$ and the yield strength which is equal to $347.082 \mathrm{MPa}$.

These findings are very close to the results of A. Amrouche and M. Su [32-31] showing through an experimental study that the existence of critical degree of expansion $\mathrm{Ce}=4.3 \%$ increases the lifetime by about 3.5 times comparing to the drilling without expansion. On the other hand, beyond this critical value the expansion process becomes detrimental on lifetime and the crack propagation rate after its initiation.

\begin{tabular}{ccccccccc}
\hline Thickness & Ce $\%$ & Ys & CRSEH & MCRS & DMCRS & DRSZ & MT & PDZ \\
\hline .6328 & 2.331 & 251.191 & 62.6207 & 156.727 & 1.2626 & 2.9075 & 13.5694 & 3.4623 \\
6.3866 & 5.7463 & 313.173 & 52.3595 & 174.271 & 2.2156 & 3.999 & 51.4983 & 4.5646 \\
4.8038 & 2.8226 & 358.838 & 143.368 & 248.403 & 0.9815 & 2.835 & 39.2896 & 3.3622 \\
6.6137 & 5.876 & 311.975 & 45.0092 & 163.664 & 2.3023 & 4.0605 & 51.2529 & 4.6291 \\
4.939 & 4.0448 & 347.082 & 115.912 & 241.729 & 1.4309 & 3.3315 & 48.4612 & 3.8708 \\
7 & 5.5078 & 250.008 & 10.0388 & 112.273 & 2.5006 & 4.2592 & 34.2554 & 4.7822 \\
5.5529 & 2.0674 & 368.755 & 161.045 & 239.242 & 0.6452 & 2.3531 & 32.5068 & 2.8971 \\
4.5671 & 4.2187 & 357.05 & 109.586 & -248.24 & 1.4403 & 3.2879 & 52.9058 & 3.869 \\
\hline
\end{tabular}

Table 3: Optimal values of residual stress profiles

The validation of the models is done by comparing the results obtained by simulations and the predicted models. Table (4) illustrating the comparison of an expansion of a $5 \mathrm{~mm}$ thick plate with a $4 \%$ degree of expansion made of aluminium alloy 6082-T6. Figure 16 shows a good correlation between residual stress profiles obtained by simulation and predicted models. 


\begin{tabular}{llll}
\hline Response & Predicted value & numerical value & Difference \% \\
CRSEH & -110 & -100 & $10 \%$ \\
MCRS & -248 & -238 & $4.2 \%$ \\
DMCRS & 1.286611 & 1.21198 & $6.15 \%$ \\
CRSZ & 2.987402 & 2.78 & $7.46 \%$ \\
MT & 54.74 & 62 & $11.7 \%$ \\
PDZ & 3.61 & 3.333 & $8.47 \%$ \\
\hline
\end{tabular}

Table 4: Predicted and numerical values.

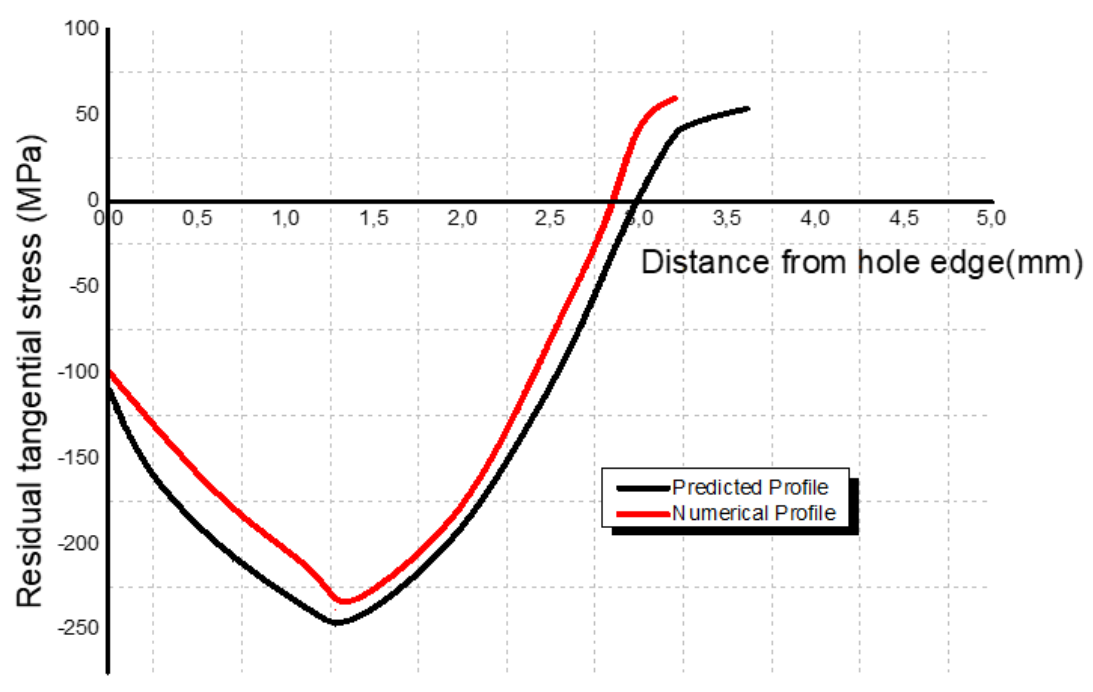

Figure16: predicted and numerical values of residual stress

This small difference between the simulation and the predicted models confirms the excellent effectiveness of the mathematical models established by the experimental design method.

\section{CONCLUSION}

$\mathrm{I}$ $\mathrm{n}$ this work, the study focuses to establish and validate a predictive model of residual stresses generated from cold hardening. Thus the assessment allows industrialists to predicting the fatigue lifetime duration of riveted or bolted structures.

An experimental setup was used to points out the effectiveness of degree of expansion, thickness of the part as well as the yield strength on the residual stresses profiles.

The application of numerical with the experimental method allows determining the optimal values of the different factors to predict the residual stress profiles for any values of the factors.

By proposing a mathematical model that takes into account these factors the latter allowed us to obtain a better description of the residual stress profile.

The validation of the model confirms the excellent quality of the mathematical model established by the experimental design method.

Based on our assessment, the effect of the degree of expansion on the improvement of the service lifetime is clearly significant than the yield strength and the thickness. Therefore, the classifications of impact parameters are in the following order: degree of expansion, the yield strength and the thickness of the structure. 


\section{REFERENCES}

[1] Chakherlou, T.N. and Vogwell, J. (2003). The effect of cold expansion on improving the fatigue life of fastener holes, Engineering Failure Analysis, 10, pp. 13-24

[2] Vogwell, J., Chakherlou, T.N. and Minguez, J.M. (2001). The effect of cold expansion on fatigue resistance of fastener holes, The 10 th international congress of fracture.

[3] Caron, I., Fiori, F., Mesmacque, G., Pirling, T., Su, M. (2004). Expanded hole method for arresting crack propagation: residual stress determination using neutron diffraction, Physica B 350 pp. e503-e505.

DOI: 10.1016/j.physb.2004.03.132.

[4] Stefanescu, D., Santisteban, J.R., Edwards, L. and Fitwpatrick, M. E. (2004). Residual Stress Measurement and Fatigue Crack Growth Prediction after Cold Expansion of Cracked Fastener Holes, Journal of Aerospace Engineering, 17 pp. 91-97. DOI: 10.1061/(ASCE)0893-1321(2004)17:3(91)

[5] Papanikos, P., and Meguid, S.A. (1998). Three dimensional finite element analysis of cold expansion of adjacent holes, International Journal of Mechanical Science, 40, pp. 1019-1028

[6] Yongshou, L., Shao, X., Liu, J. and Yue, Z. (2010). Finite element method and experimental investigation on the residual stress fields and fatigue performance of cold expansion hole, Materials and Design, 31, pp. 1208-1215.

DOI: $10.1016 /$ j.matdes.2009.09.031

[7] Cheol, K., Dae-Jin, K., Chang-Sung, S. and Won-Ho, Y. (2004). Finite element analysis of the residual stress by cold expansion method under the influence of adjacent holes, Journal of Materials Processing Technology, pp 986-991. DOI: $10.1016 /$ j.jmatprotec.2004.04.271

[8] Aghdam, A.B., Chakherlou, T.N. and Saeedi, K. (2010). An FE analysis for assessing the effect of short-term exposure to elevated temperature on residual stresses around cold expanded fastener holes in aluminum alloy 7075-T6.Materials and Design, 31, pp. 500-507. DOI:10.1016/j.matdes.2009.06.024

[9] Amrouche, A., Mesmacque, G., Garcia, S. and Talha, A. (2003), Cold expansion effect on the initiation and the propagation of the fatigue crack, International Journal of Fatigue, 25, pp. 949-954.

DOI:10.1016/S0142-1123(03)00127-0.

[10] Özdemir, A.T. and Hermann, R. (1999). Effect of expansion technique and plate thickness on near-hole residual stresses and fatigue life of cold expanded holes, journal of materials science, 34. Pp. $1243-1252$.

[11] Salvati, E., Lunt, A.J.G., Ying, S., Sui, T., J.Zhang, H., Heason, C., Baxter, G. and Korsunsky, A.M. (2017). Eigenstrain reconstruction of residual strains in an additively manufactured and shot peened nickel superalloy compressor blade, journal of Computer Methods in Applied Mechanics and Engineering, 320, pp 335-351.

DOI: 10.1016/j.cma.2017.03.005.

[12] DeWald, A T., Hill, M R. (2008) Eigenstrain-based model for prediction of laser peening residual stresses in arbitrary three-dimensional bodies Part 2: Model verification, Journal of Strain Analysis for Engineering Design, 44, pp.13-27. DOI: $10.1243 / 03093247$ JSA420.

[13] Renan, L., Ribeiro and Michael, R. Hill. (2017). Residual Stress From Cold Expansion of Fastener Holes: Measurement, Eigenstrain, and Process Finite Element Modeling, J. Eng. Mater. Technol 139(4), 041012, Paper No: MATS-17-1032. DOI: $10.1115 / 1.4037021$.

[14] Matos, P. D., Moreira, P., Camanho, P. and De Castro, P. (2005). Numerical simulation of cold working of rivet holes, Finite elements in analysis and design, 41, pp. 989-1007.

[15] Kang, J., Johnson, W.S. and Clark, D.A. (2002). Three-dimensional finite element analysis of the cold expansion of fastener holes in two aluminum alloys, Journal of engineering materials and technology, 124, pp. 140-145.

[16] Bernard, M., Bui-Quoc, T., Julien, D. and Forgues, SA. (1993). Feasibility study of cold expansion process modelling. Canadian Department of Defence, Research and Development Air, Cont. Rep. W8477-1-AC89101-SS;

[17] Burlat, M., Julien, D., Lévesque, M., Bui-Quoc, T. and Bernard, M. (2008). Effect of local cold working on the fatigue life of 7475-T7351 aluminium alloy hole specimens, Engineering Fracture Mechanics, 75, pp. 2042-2061.

DOI: $10.1016 /$ j.engfracmech.2007.10.011

[18] Mahendra Babu, N., Jagadish, T., Ramachandra, K. and Sridhara, S. (2008). A simplified 3-D finite element simulation of cold expansion of a circular hole to capture through thickness variation of residual stresses, Engineering Failure Analysis, 15, pp. 339-348.

[19] ABAQUS standard User's manual, Karlsson and Sorensen, (2005).

[20] Laroche, Y. and Narcisse, J. (2011) Rapport : Projet de Fin d'Etude Simulation numérique de l'usinage avec ABAQUS, polytech tours. 
[21] Clausen, A. H., Borvik, T., Hopperstad, O. S. and Langseth, M (2003) Impact resistance of AA6005 panels , journal . IV France 110, DOI: 10. 1051/p4 : 20030774.

[22] Jaspers, S.P.F.C., Dautzenberg, J.H. (2002). Material behavior in conditions similar to metal cutting: flow stress in the primary shear zone, Journal of Materials Processing Technology, 122, pp. 322-330.

[23] Liu, J., Shao, X.J., Liu, Y.S. and Yue, Z.F (2008). Effect of cold expansion on fatigue performance of open holes, Materials Science and Engineering, A 477, pp. 271-276. DOI:10.1016/j.msea.2007.05.034

[24] Elajrami, M., Miloud, R., Melouki, H. and Boukhoulda, F. (2013) Numerical study of the effect of doublecold expansion of rivet hole on the residual stresses distribution, journal of Engineering Manufacture, 227(4), pp. 621-626.

DOI: $10.1177 / 0954405412472179$.

[25] Eriksson, L., Johansson, E., Kettaneh-Wold, N., Wikström, C. and Wold, S., (2000). Design of experiments: Principles and applications, Stockholm, Learnways AB.

[26] https://www.dynacentrix.com/telecharg/Modde/Livredoe.pdf.

[27] MODDE 5.0, Modelling and Design, Umetrics AB, Umea, Sweden. (1999).

[28] Medjdoub, S. and Bouadjra, B., (2018). Optimization of the geometrical parameters of bonded composite wrap for repairing cracked pipelines, J. Frattura ed Integrità Strutturale, 46, pp. 102-112; DOI: 10.3221/IGF-ESIS.46.11.

[29] Nigrelli, V. and Pasta, S. (2008). Finite-element simulation of residual stress induced by split-sleeve cold-expansion process of holes, journal of materials processing technology, 205, pp. 290-296. DOI:10.1016/j.jmatprotec.2007.11.207.

[30] Semari, Z. Influence des perçages, avec et sans expansion, en fond de fissure sur la propagation des fissures de fatigue. Cas des alliages d'aluminium A6082 et A6005. Etude expérimentale et numérique,Thèse de Doctorat, jui 2013, Université des Sciences et Technologies de sidi bel abbés.

[31] Semari, Z., Aid, A., Benhamena, A., Amrouche, A., Benguediab, M., Sadok, A. and Benseddiq, N. (2013). Effect of residual stresses induced by cold expansion on the crack growth in 6082 aluminum alloy, Engineering Fracture Mechanics, 99, pp. 159-168. DOI: 10.1016/j.engfracmech.2012.12.003.

[32] Matos, P.F.P., McEvily, A.J., Moreira, P.M.G.P. and Castro, P.M.S.T. (2007). Analysis of the effect of cold-working of rivet holes on the fatigue life of an aluminum alloy.International Journal of Fatigue, 29, pp. 575-586.

DOI: 10.1016/j.ijfatigue.2006.04.004

[33] Man, S. (2005). Etude de l'Influence et de l'Optimisation du Degré d'Expansion à Froid dans les Mécanismes de Réamorçage d'une Fissure : Etude Numérique et Expérimentale, Thèse de Doctorat, Université des Sciences et Technologies de Lille.

[34] Amrouche, A., Su, M., Aid, A. and Mesmacque, G.(2008). Numerical study of the optimum degree of cold expansion: Application for the pre-cracked specimen with the expanded hole at the crack tip, journal of materials processing technology, 197, pp. 250-254. DOI: 10.1016/j.jmatprotec.2007.06.030. 